\title{
Signos Radiológicos: El Signo de la Galaxia
}

\author{
Dres. Rodrigo Araya ${ }^{(1)}$, Gonzalo Pérez $O^{(1)}$, Devis Castro $C^{(1)}$, Felipe Sánchez $T^{(2)}$, Juan Carlos Díaz $P^{(3)}$, Vivianne Agar $F^{(4)}$.
}

1. Becado de Radiología, Centro de Imagenología Hospital Clínico Universidad de Chile. Santiago, Chile.

2. Becado de Radiología, Universidad de los Andes. Santiago, Chile.

3. Médico radiólogo. Unidad de tórax. Servicio de Radiología. Hospital Clínico Universidad de Chile. Santiago, Chile.

4. Médico Broncopulmonar, Clínica Alemana de Santiago. Santiago, Chile.

\section{Radiology Signs: The Galaxy Sign}

Abstract: The galaxy sign represents a mass-like lesion, composed of innumerable coalescing granulomatous nodules, more concentrated in the center than at the periphery. It was initially described in patients with sarcoidosis, and was referred to as the "sarcoid galaxy" sign. It is now known to be present in other entities such as tuberculosis, lung cancer and the pulmonary fibrosis mass of pneumoconiosis. Its identification and adequate interpretation is important, given that in association with other tomographic signs it allows an orientation toward the diagnosis of sarcoidosis.

Keywords: Granuloma, Sarcoidosis, Tuberculosis.

Resumen: El signo de la galaxia representa una lesión tipo masa, compuesta por innumerables nódulos granulomatosos coalescentes, más concentrados en el centro que en la periferia. Inicialmente se describió en paciente con sarcoidosis, y se denominó el signo de la galaxia sarcoidea. Actualmente se sabe que puede estar presente en otras entidades como la tuberculosis, el cáncer pulmonar y la fibrosis pulmonar masiva de las neumoconiosis. Es importante su identificación y adecuada interpretación, dado que en asociación con otros signos tomográficos permite una orientación al diagnóstico de sarcoidosis.

Palabras clave: Granulomas, Sarcoidosis, Tuberculosis.

Araya R, Pérez G, Castro D, Sánchez F, Díaz JC, Agar V. Signos Radiológicos: El Signo de la Galaxia. Rev Chil Radiol 2014; 20(3): 113-115.

Contacto: Rodrigo Araya R. / araya.rj@hotmail.com

Trabajo recibido el 20 de mayo de 2014. Aceptado para publicación el 20 de julio de 2014.

\section{Reseña Histórica}

El año 2002 se publicó un estudio descriptivo centrado en buscar características comunes para los grandes nódulos pulmonares observados ocasionalmente en la sarcoidosis. Hasta ese momento eran bien conocidos los rasgos de los nódulos pequeños que se presentan de forma típica en ésta, pero no existían descripciones detalladas acerca de los nódulos mayores a $1 \mathrm{~cm}$ (definidos como nódulos grandes). En dicho estudio se revisaron retrospectivamente las TC de pacientes con diagnóstico histológico de sarcoidosis y se analizaron dirigidamente las características de los nódulos mayores a $1 \mathrm{~cm}$. Se reportó que la estructura de todos los grandes nódulos pulmonares encontrados se asemejaba la imagen de una galaxia, entendida como la "conjunción de numerosas estrellas". Lo anterior fue descrito por los autores como el "signo de la galaxia sarcoidea"(1).

\section{Aspecto Imagenológico}

Este signo corresponde a un nódulo central irregular, formado por la confluencia de múltiples nódulos más pequeños que están menos concentrados en la periferia lo que genera un borde irregular con múltiples imágenes satélites (Figura 1). El tamaño promedio de los nódulos es de 1 a $2 \mathrm{~cm}^{(3)}$.
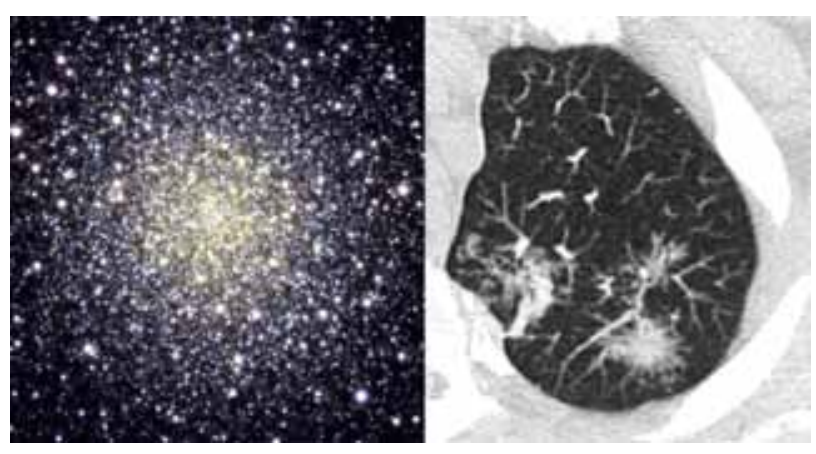

Figura 1. a) Cúmulo globular M92 en la constelación de Hércules. b) Corte axial de tomografía computada de tórax. En el lóbulo superior izquierdo se observa un nódulo central con otros nódulos periféricos marginados de menor tamaño, consistente con el signo de la galaxia. 


\section{Significado}

El signo de la galaxia representa un conglomerado de granulomas en el intersticio pulmonar que se hacen inseparables y que están menos concentrados en la periferia ${ }^{(1,2)}$.

\section{Diagnóstico diferencial}

Si bien este signo se describió por primera vez en la sarcoidosis pulmonar, actualmente se considera poco específico como elemento único, ya que están descritas en la literatura otras enfermedades granulomatosas que lo presentan, especialmente la tuberculosis pulmonar ${ }^{(2)}$. También se puede confundir imagenológicamente con cáncer pulmonar y con fibrosis masiva progresiva ${ }^{(3)}$.

\section{Discusión}

El signo de la galaxia histopatológicamente representa un conglomerado de granulomas intersticiales que pueden estar presente tanto en la sarcoidosis como en pacientes con tuberculosis. Lo que ayuda para orientar el diagnóstico diferencial son los hallazgos imagenológicos asociados. En la sarcoidosis se observa una distribución bilateral y múltiple del signo, con compromiso simétrico en todos los lóbulos pulmonares (Figura 2). La presencia de adenopatías hiliares-mediastínicas extensas, que pueden calcificar se observan en el $95 \%$ de las sarcoidosis, por lo que son altamente sugerentes del diagnóstico ${ }^{(1,3,4)}$. Los granulomas sarcoideos peribroncovasculares producen un engrosamiento irregular del haz broncoarterial, lo cual también es orientador de sarcoidosis ${ }^{(4)}$.

En el año 2005, se reportó en 8 pacientes con tuberculosis activa la presencia de un "conglomerado de pequeños nódulos" mayor a $1 \mathrm{~cm}$ que era indistinguible de la galaxia sarcoide reportada anteriormente ${ }^{(2)}$. En dicho estudio se concluyó que el conglomerado no correspondía a tuberculomas ni a nódulos de diseminación endobronquial, y basado en el origen granulomatoso de la tuberculosis y de la sarcoidosis se planteó una histología común. El signo se presentó aislado en 4 de los 8 casos y la mayoría se localizaba en lóbulos superiores o en el segmento superior del lóbulo inferior. Sólo uno presentó linfadenopatías hiliares o mediastínicas. Por lo tanto, es más sugerente de tuberculosis el signo de la galaxia único, en lóbulos superiores con árbol en brote y sin la presencia de adenopatías ${ }^{(2,3)}$.

En la misma serie, todos los "conglomerados de nódulos pequeños" se resolvieron con el tratamiento antituberculoso y el $50 \%$ de los casos no presentaba hallazgos tomográficos de actividad de la enfermedad como árbol en brote, engrosamiento bronquiolar o nódulos centrolobulillares. Por lo que también sería importante considerar que el signo de la galaxia en pacientes con tuberculosis sería un indicador indivi- dual de actividad ${ }^{(2,3)}$.

Los nódulos satélites en la periferia del nódulo central pueden dar la impresión de que están fusionados y por lo tanto parecen espiculaciones, que son características de la fibrosis peritumoral en el cáncer de pulmón. Sin embargo, un cáncer pulmonar menor de $3 \mathrm{~cm}$, que es el tamaño habitual reportado de la galaxia sarcoide, tiene una baja incidencia de
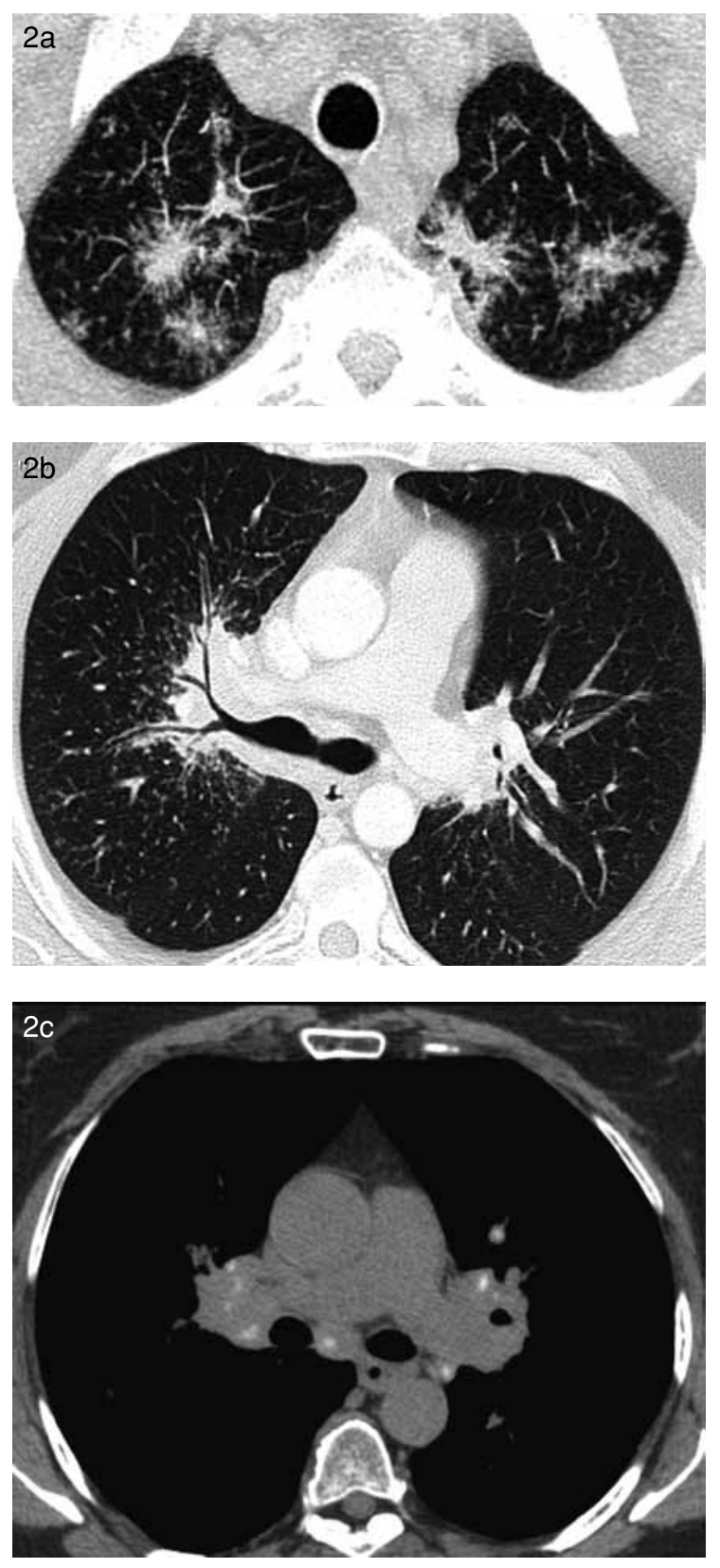

Figura 2. Paciente con diagnóstico de sarcoidosis pulmonar. Cortes axiales de tomografía computada de tórax. $a, b)$ En la ventana pulmonar se aprecian conglomerados bilaterales de nódulos pulmonares con el aspecto de galaxia. También se observa un engrosamiento del intersticio axial peribroncovascular asociado a nódulos con distribución perilinfática. c) La ventana mediastínica muestra la presencia de adenopatías calcificadas hiliares bilaterales y subcarinales (mediastínicas). 
adenopatías mediastínicas e hiliares ${ }^{(5)}$. Por lo tanto, la presencia de extensas adenopatías hiliares y mediastínicas y en especial calcificadas es más sugerente de sarcoidosis.

El signo de la galaxia puede estar presente en la fibrosis masiva progresiva de las neumoconiosis, en especial silicosis y la enfermedad del carbón ${ }^{(1,3,4)}$. En estos casos corresponde a conglomerados de nódulos silicóticos asociado a tejido fibroso denso y cicatricial. Para realizar el diagnóstico diferencial es fundamental el antecedente clínico de exposición sumado a las imágenes, donde es característico la presencia de opacidades grandes e irregulares mayores a $1 \mathrm{~cm}$,
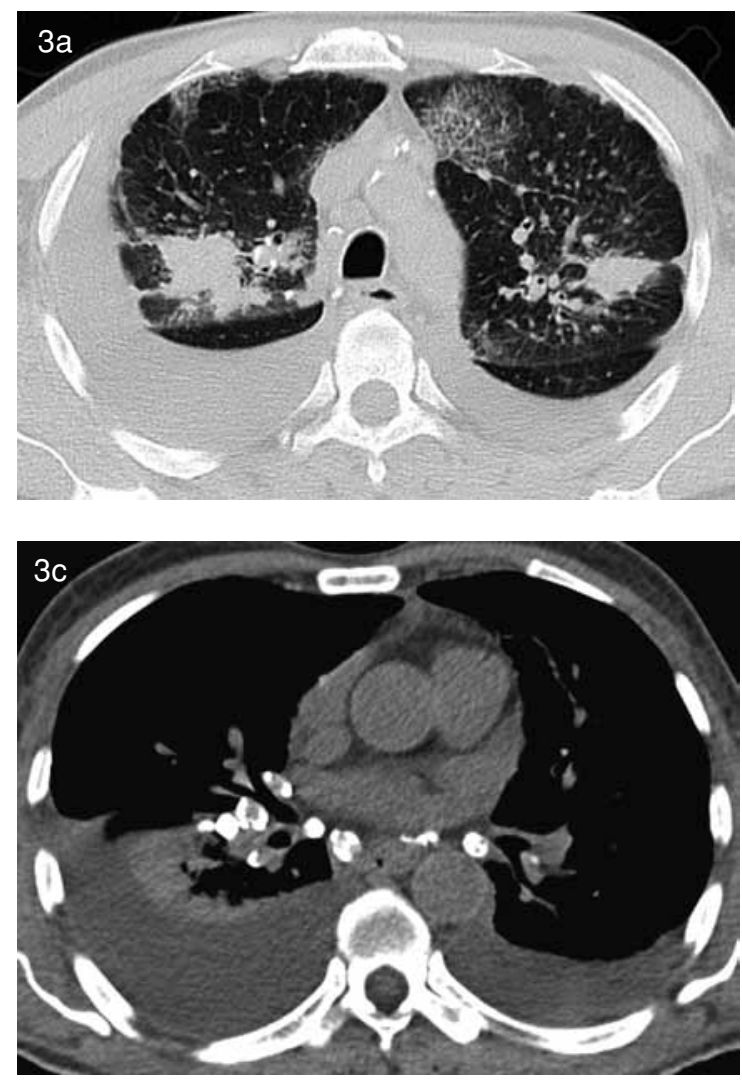

\section{Bibliografía}

1. Masashi N, Hiroto H, Kenji M, Hidemasa U, Yoshiharu O, Koichi N, et al. Large coalescent parenchymal nodules in pulmonary sarcoidosis: "sarcoid galaxy" sign. AJR Am J Roentgenol 2002; 178: 1389-1393.

2. Jeong-Nam H, Yo Won C, Seok Chol J, Choong Ki P. Pulmonary Tuberculosis: Another Disease Showing Clusters of Small Nodules. AJR Am J Roentgenol 2005; 184: 639-642.

3. Aikins A, Kanne J, Chung J. Galaxy Sign, J Thorac bilaterales, parahiliares en lóbulos superiores o en lóbulo medio, con disminución de volumen y distorsión de la arquitectura pulmonar, bronquiectasias por tracción, enfisema paracicatricial y nódulos de distribución perilinfática. También presentan adenopatías mediastínicas calcificadas (Figura 3 ).

\section{Conclusión}

El signo de la galaxia es un signo tomográfico útil para el diagnóstico de sarcoidosis pulmonar si se asocia a los hallazgos imagenológicos característicos. Es muy importante el diagnóstico diferencial con tuberculosis y neoplasia por las implicancias terapéuticas y pronósticas que conlleva.

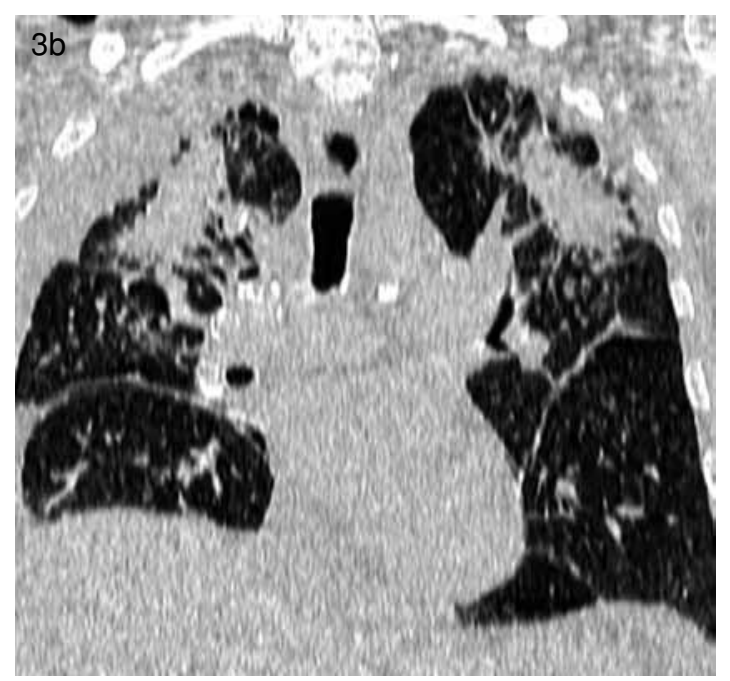

Figura 3. Silicosis pulmonar con fibrosis masiva progresiva. a, b) Corte axial y coronal de tomografía computada de tórax en ventana pulmonar, se observan opacidades grandes e irregulares perihiliares en ambos lóbulos superiores que representan la expansión y confluencia de los nódulos silicóticos, se asocia a nódulos prilinfáticos. c) Adenopatías calcificadas hiliares y mediastínicas, algunas de ellas presentan calcificación en la periferia, dando un aspecto en cáscara de huevo, lo cual es sugestivo pero no específico de silicosis. El derrame pleural tenía otra etiología en este caso.

Imaging 2012; 27: 337-338.

4. Criado E, Sánchez M, Ramírez J, Arguis P, de Caralt TM, Perea RJ, et al. Pulmonary Sarcoidosis: Typical and Atypical Manifestations at High- Resolution CT with Pathologic Correlation. RadioGraphics. 2010; 30: 1567-1586.

5. Takizawa T, Terashima M, Koike T, Akamatsu H, Kurita Y, Yokoyama A. Mediastinal lymph node metastasis in patients with clinical stage I peripheral non-small-cell lung cancer. J Thorac Cardiovasc Surg 1997; 113: 248-252. 